مقايسه حافظه كوتاهمدت و بلندمدت در مردان معتاد به ترياك، معتاد ترك كرده

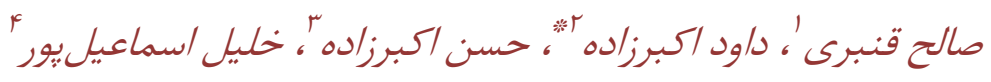
'كارشناسى ارشد روانشناسى بالينى، دانشكاه آزاد اسلامى واحد علوم و تحقيقات، تبريز، ايران

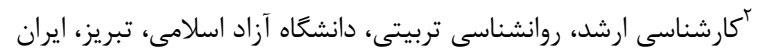

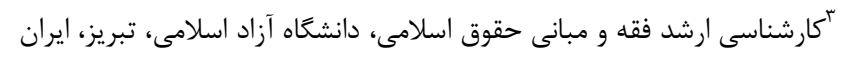

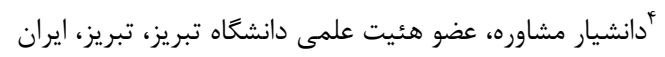

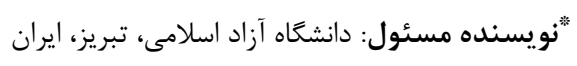

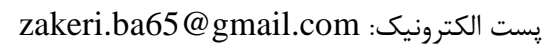

جكيداיه

زمينه و هدف: اعتيان يك بيمارى جسمى، روانى، اجتماعى و معنوى /ست و يكى از آسيبهاى جدى به

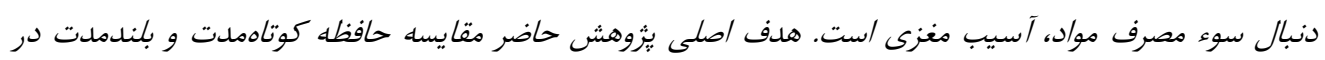

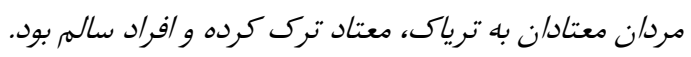

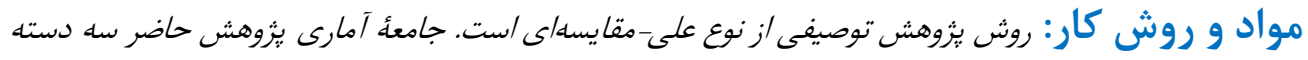

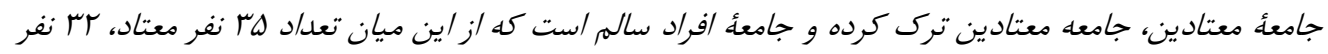

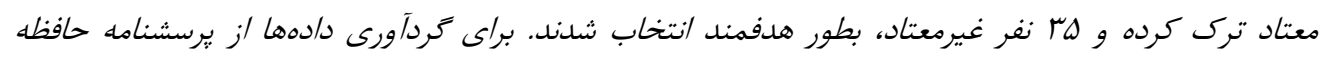

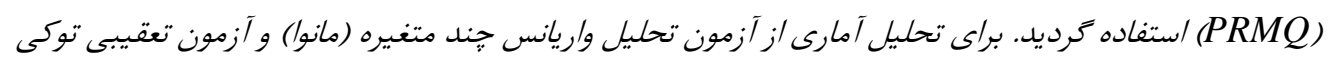

استفاده شد.

يافتنه ها: نتايج بزوهش نشان داد كه بين ميانَحين معتادان، معتادان ترك كرده و افراد عادى در عملكرد حافظه

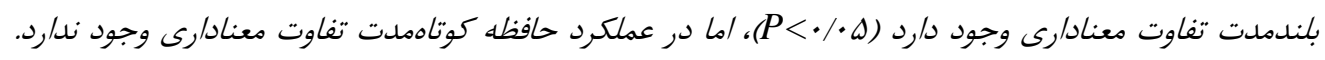

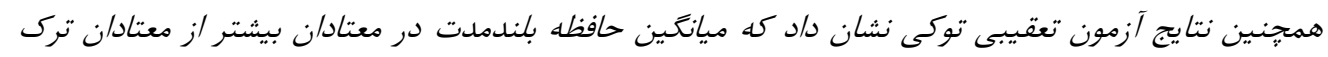
كرده و افراد عادى /ست. نتيجهلَيرى: بنابراين افزايش طول مدت اعتياد باعث تخريب بيشتر حافظه بلندمدت شده و در نتيجه ترى اعتياد را مشكلتر مىسازد. وازه هاى كليدى: حافظه كوتاهدت، حافظه بلندمدت، معتاد، معتاد ترك كرده، افراد سالمر. 
از سويى يكى از آسيبهاى جدى به دنبال سوء مصرف مواد، آسيب مغزى است. آسيب مغزى و نقصهاى شناختى همراه با سوء مصرف مزمن مواد مخدر و داروها،

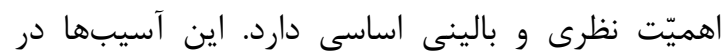

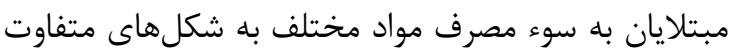
ديده مىشود و در اين زمينه مطالعات متعددى انجام شده

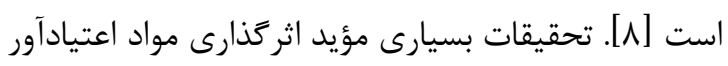
بر مغز و در نتيجه اثر بر روى توانايىهاى شناختى

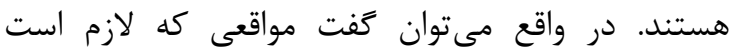
مطلبى فقط به مدت خند ثانيه به خاطر سيرده شود، با لإن

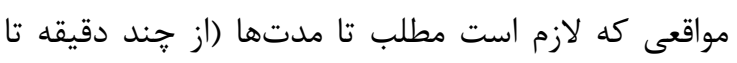
קند ثانيه) در ياد بماند، حافظه به اشكال متفاوتى عمل

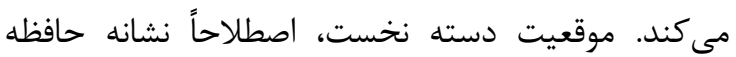

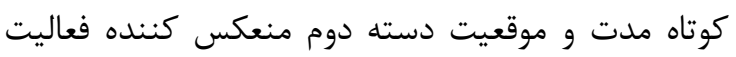

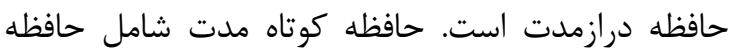
هايى است كه ثانيه هايى يا حداكثر دقايقى به طول ميى دانى

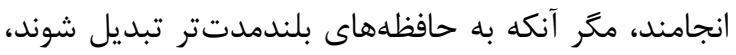

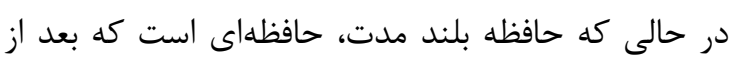

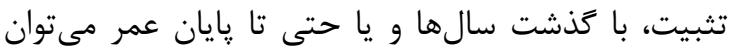

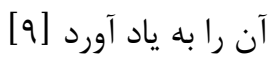

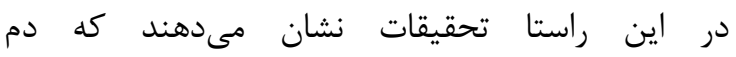
اسبى(هييوكامٍ)، ساختارى در مغز كه زير قشر مخ و

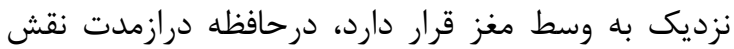

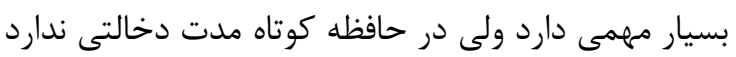

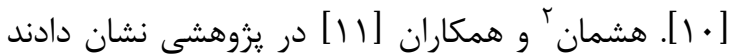
كه مصرف انواع مواد روانگردان مىتوانند اثرات زيانبارى بر روى حافظه و عملكرد شناختى افراد داشته باشد.

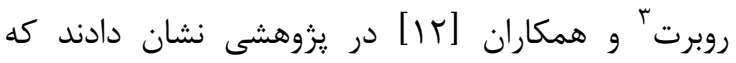
مصرف كنندكان اكستازى به طور معنادارى در حافظه و يادگيرى نسبت به گروه كنترل و مصرف كنند

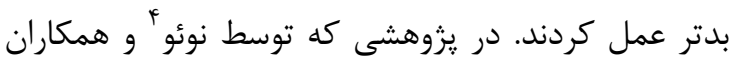

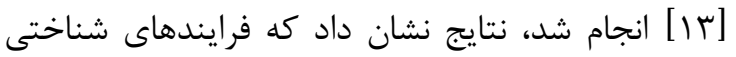

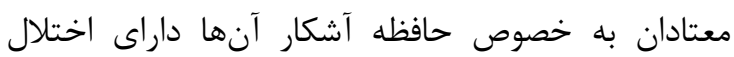

\section{2- Heishman}

3- Roberts

4- Noe

اعتياد يك بيمارى جسمى، روانى، اجتماعى و معنوى است

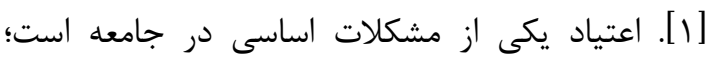

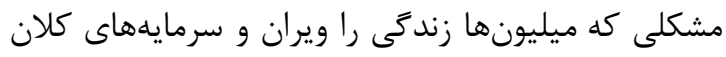

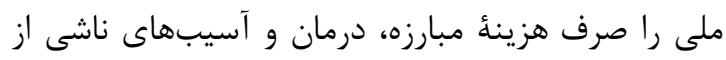

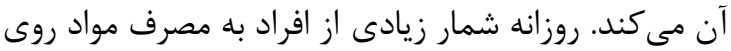

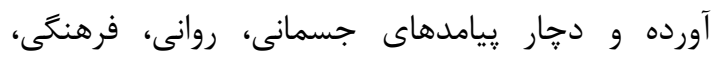
اقتصادى و اجتماعى ناشى از آن مىشوند. كشور ما نيز بنا به برخى دلايل فرهنگى، باورهاى اشتباه و موقعيت آنسي

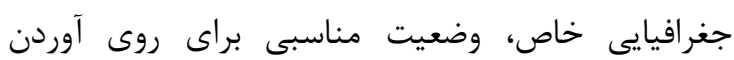

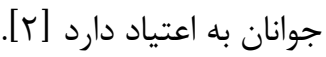

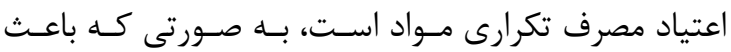
شكست در كار، تحصيل، نقشهاى خانوادىى يا موقعيـت

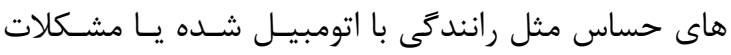
قانونى مربوط به مصرف مواد ايجاد مى كند [ـ]. از تبعـات آندات

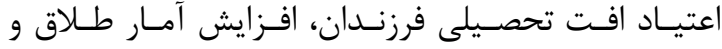

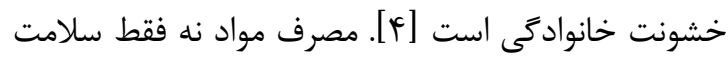
فرد، بلكه سلامت خانواده و جامعه را نيز به مخاطره مسى اندازد و موجب انحطاط روانى و اخلاقى فرد مى شــود [هـ].

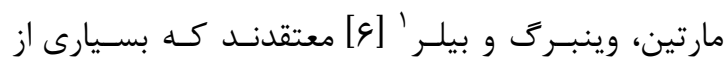

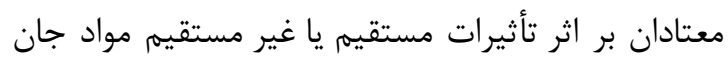

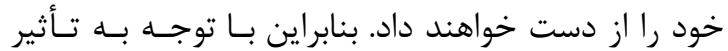

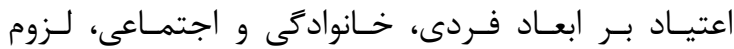

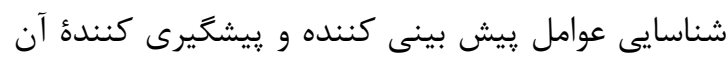

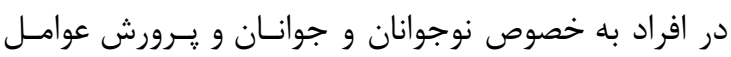
محافظت كننده در برابر اعتياد بيش از بيش احساس مئ-

در اعتياد به مواد مخدر، تغييرات عصب شناختى اختيار انسان را تحت تأثير قرار داده و فرد معتاد به استفاده

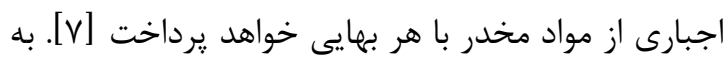

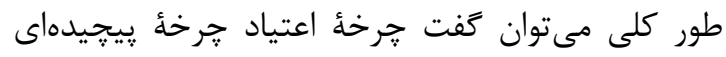
است كه از يك سو، فرآيندى نورو فيزيولوزيكى و از سون إني ديخر، فرايندى روانشناختى است كه اين تغييرات نورو

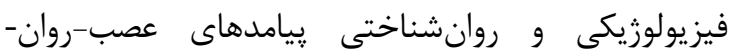
شناختى را به دنبال خود ايجاد مى كنند.

\section{1- Martin, Weinberg, Bealer}


از آموزشها و تجويز درمانكران خود، فرايند ترك اعتياد را ران راحتتر يشت سر بكذارند و از خطر بركشت دوباره به

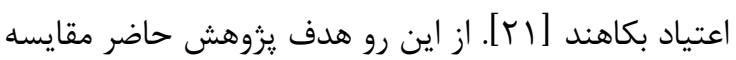

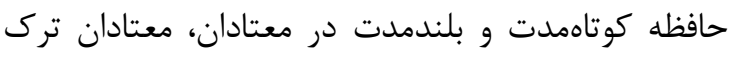

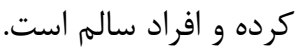

\section{روشىكار}

روش يزوهش توصيفى از نوع على- مقايسهاى بود. جامعأه

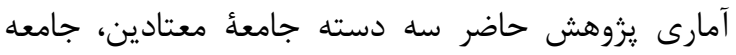
معتادين ترك كرده و جامعأ افراد سالم است. جامعأ آمارى معتادين، شامل معتادين مصرف ترياك مراجعه- تردئ

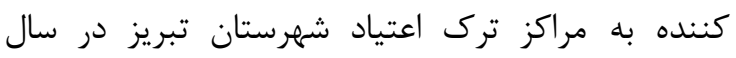

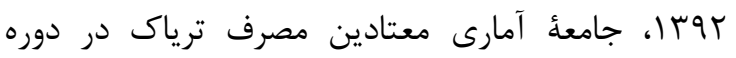
ترك، شامل معتادين بسترى شده در كمبهاى ترى

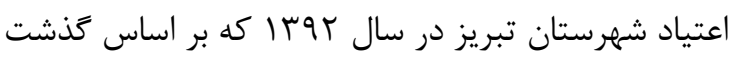
حداقل يك ماه از بسترى شدن در مركز و واينكه هيجز كونه

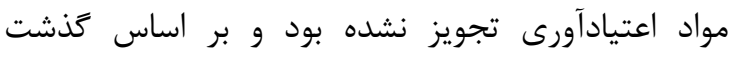

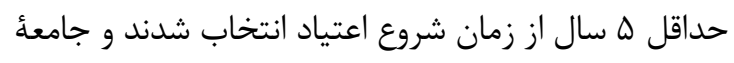

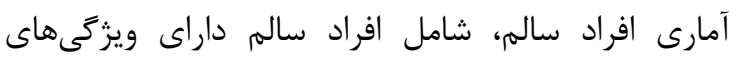
جمعيتشناختى (سن، جنس و تحصيلات) مشابه با افراد نمونهٔ معتاد از اين شهرستان مىباشند. نمونهُ معتادان بهن

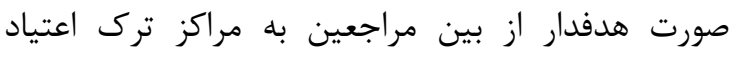

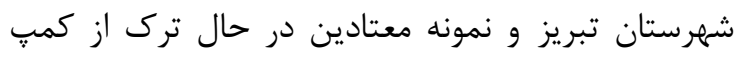

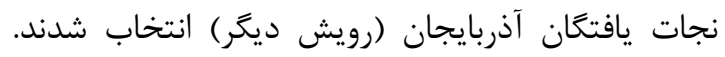

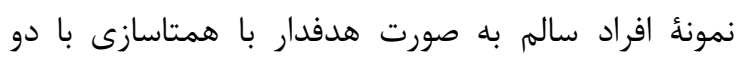
كروه مذكور و با كنترل متغيرهاى سن و تحصيلات از بين

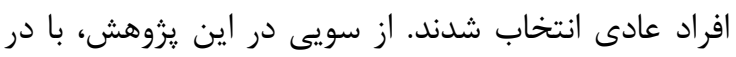

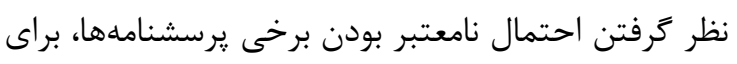

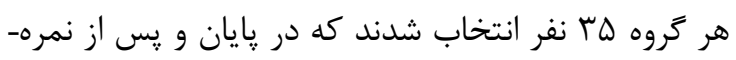

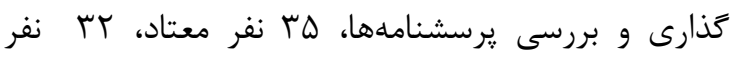

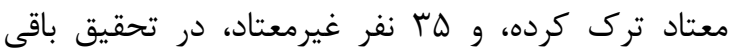

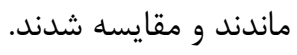

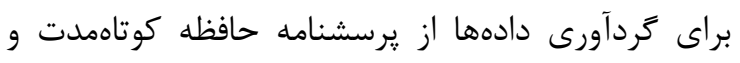

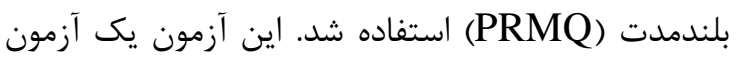

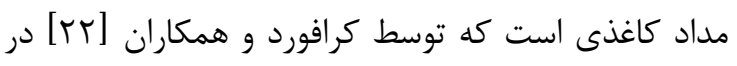

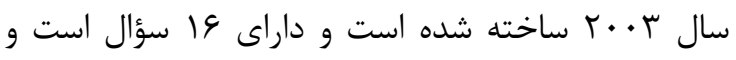

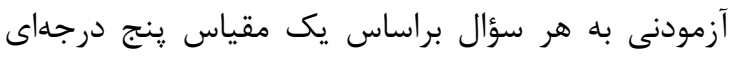

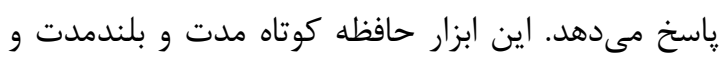

از سويى در تحقيقى نشان داده شد كه مصرف كنندگان

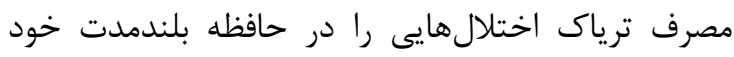

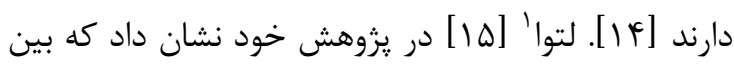

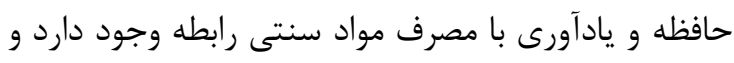

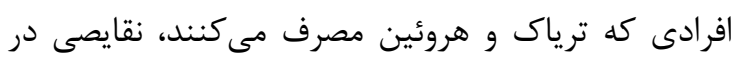

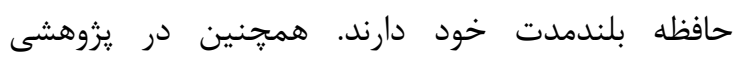

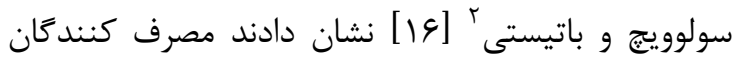
مواد اختلال هايى را در حافظه رمزكردانى، ذخيره،

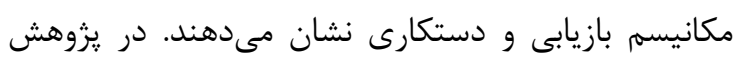

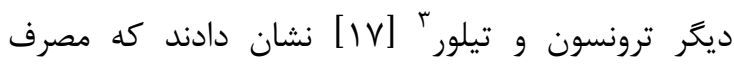

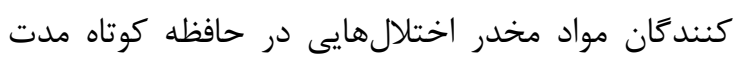

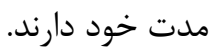
همجنين به نظر مىرسد كه بخشى دارند از علل بركشت اعتياد

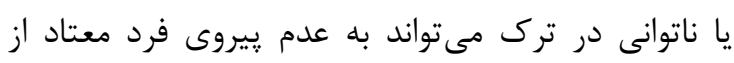

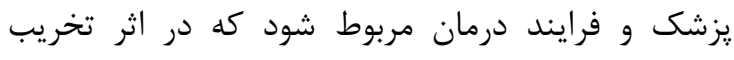

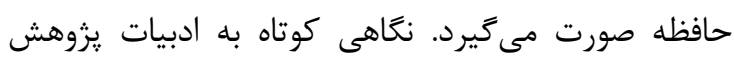

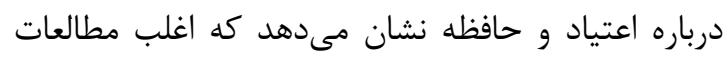

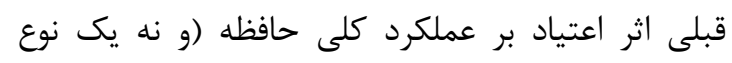

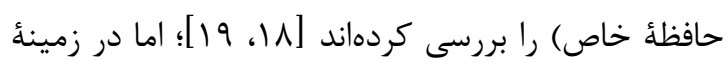

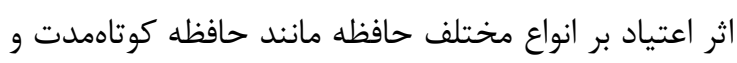
بلندمدت، مطالعات كم بوده و فقط برخى مطالعات اثر اين

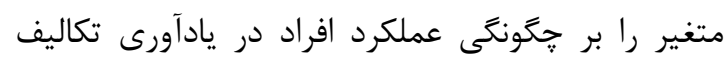

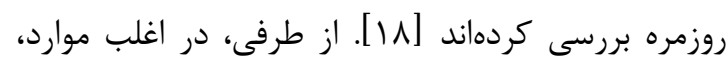
تحقيقات موجود فقط به مقايسه اختلالات عصب- روان-

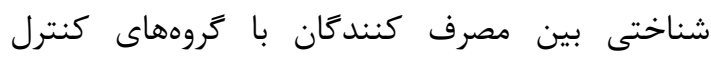

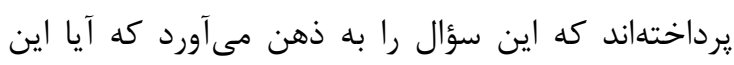

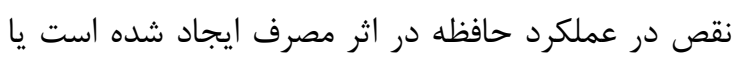

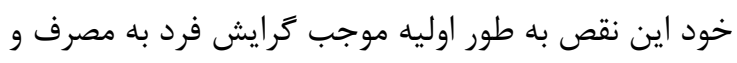

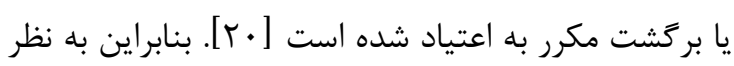

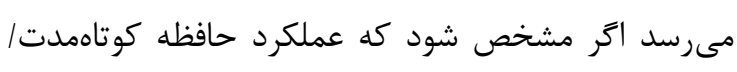

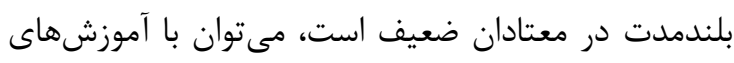
مرتبط و تلاش براى ترميم حافظه به معتادان كمك مع كرد

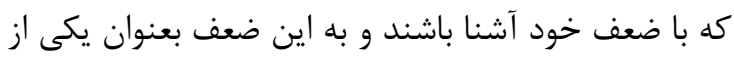

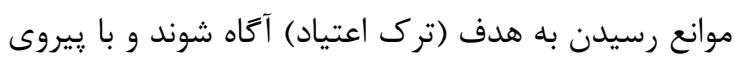

1-Latvala

2- Solowij, Battisti 3 -Tronson, Taylor 
در جدول ا ميانخين و انحراف معيار متغيرهاى يزوهش نشان داده شده است. مندرجات جدول ا نشان مىدهد كه ميانگين نمرات در حافظه عمومى، كوتاهمدت و بلندمدت در افرات مراد معتاد بيشتر از معتادان ترك كرده و افراد عادى است. همجنين ميانگين هر سه حافظه در معتادان ترك كرده بيشتر از افراد عادى است. براى سنجش اين مسأله كه بين معتادان، معتادان ترى ادى إدى كرده و افراد عادى در كدام يك از انواع حافظه تفاوت وجود دارد، از تحليل واريانس جند متغيره استفاده شد كه نتايج مربوط به آن در جدول ب ارائه شده است.

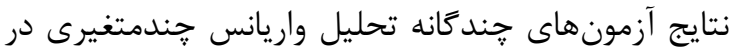
جدول r نشان مى بدهد، تفاوت بين گروههاى مورد مقايسه در تركيب خطى حافظه كوتاهمدت و بلندمدت معنادار

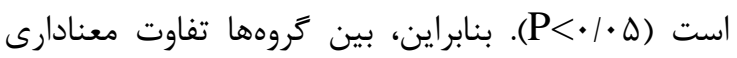
حداقل در يكى از انواع حافظه (كوتاهمدت و بلندمدت) وجود دارد. بررسى مفروضههاى اصلى تحليل واريانس جندمتغيرى نشان داد كه در آزمون باكس، مفروضه يكسانى ماتريس واريانس- كوواريانس برقرار است (هـ/T= P

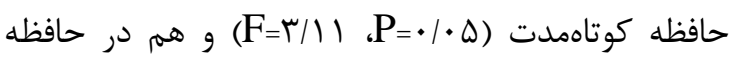

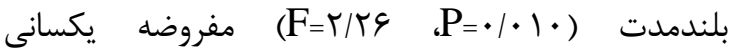

$$
\text { واريانسها در سه گروه برقرار است. }
$$

همجنين با توجه به مندرجات جدول r مشاهده مىشود

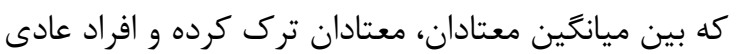

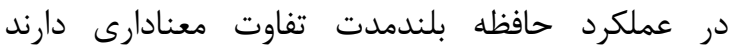

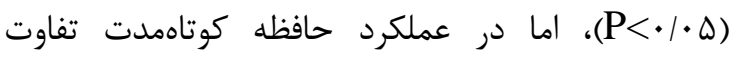

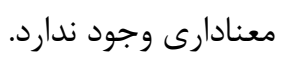

يك مقياس كلى با عنوان حافظه عمومى دارد كه از مجموع آنها بدست مىآيد. اين آزمون در اصل ميزان خطاى حافظه كلى و زيرمقياسهاى آن را نشان مئ آندهد.

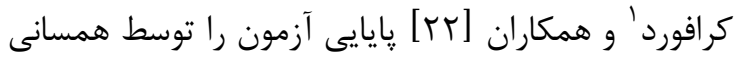
درونى (آلفاى كرونباخ) در مقياس كوتاهمدت، بلندمدت و ورن

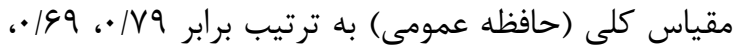

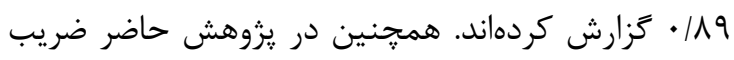
آلفاى كرونباخ براى اين برسشنامه براى حافظه كوتاهمدت،

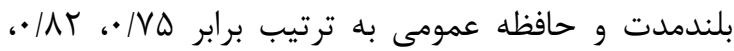
| l PV يس از گردآورى دادهها به منظور تجزيه و تحليل دادهها از

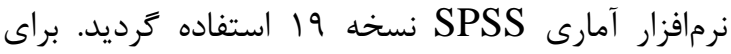
تحليل آمارى از آزمون تحليل واريانس جند آمارى متغيره (مانوا) و آزمون تعقيبى توكى استفاده شد.

\section{يافته ها}

از نظر ويزگَىهاى جمعيتشناختى، ميانگين سن شركت

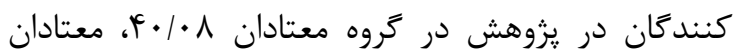

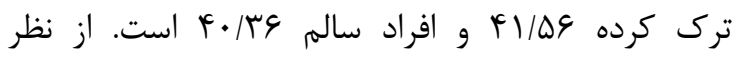

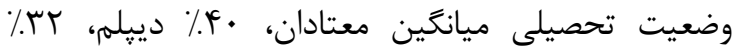

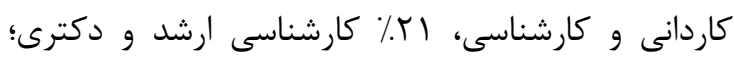

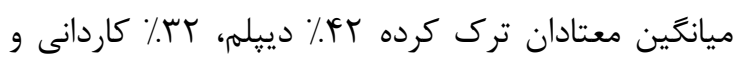
كارشناسى و •r/ كارشناسى ارشد و دكترى؛ ميانگين

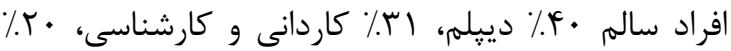

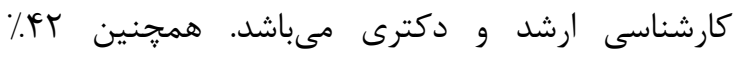

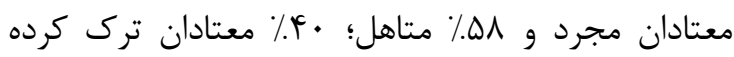

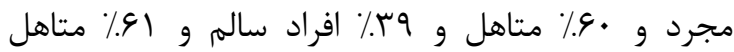

\begin{tabular}{|c|c|c|c|}
\hline افراد سالم & معتادان ترك كرده & معتادان & كروه ها \\
\hline 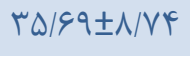 & $r N / \cdot I \pm 1 / / r$ & $p \cdot 1 \cdot q \pm 11 / r q$ & حافظه عمومى \\
\hline$|\Lambda / V| \pm Y / T \mid$ & 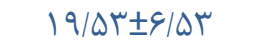 & $r \cdot|V| \pm r / \cdot q$ & حافظه كوتاه مدت \\
\hline 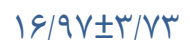 & $|\Lambda / \Delta \cdot \pm \Delta /| \Lambda$ & $r \cdot / \mathcal{R}+\Delta / \mathbb{R}^{c}$ & حافظه بلند مدت \\
\hline
\end{tabular}

جدول ا: ميانكين و انحراف معيار نمرات شركت كنندكان در حافظه عمومى و انواع آن 


\begin{tabular}{|c|c|c|c|c|c|c|}
\hline اندازه اثر & سطح معنادارى & $\mathrm{F}$ & MS & $\mathrm{df}$ & $\mathrm{SS}$ & متغير وابسته \\
\hline.$/ \cdot r \Delta$ & $\cdot / r \Lambda$ & T/EF & $11 \cdot / 9$ & 1 & $11 \cdot / 9$. & حافظه كوتاهمدت \\
\hline$\cdot / \cdot \lambda F^{k}$ & $.1 \cdot 1$ & $F / \Delta r$ & $r \mu \cdot r$. & 1 & $r \mu \cdot r$. & حافظه بلندمدت \\
\hline
\end{tabular}

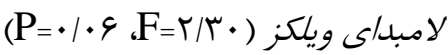

\begin{tabular}{|c|c|c|c|}
\hline افراد عادى & معتاد ترى كرده & زروه & نوع حافظه \\
\hline the & $1 / 94$ & معتادان & \multirow[t]{3}{*}{ حافظه بلندمدت } \\
\hline $1 / \Delta T$ & - & معتاد ترى كرده & \\
\hline - & & افراد عادى & \\
\hline
\end{tabular}

$\star * . \mathrm{P}<\cdot 1 \cdot 1$

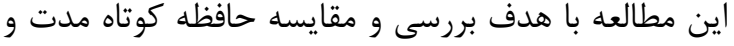
بلندمدت در بيماران معتاد، ترك كرده و افر افراد سالم انجام كرفت. نتايج اين مطالعه نشان داد كه بين معتادان و افراد عادى تفاوت معنادارى در عملكرد حافظه بلندمدت وجود

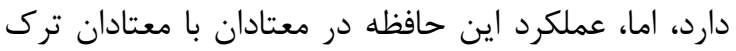

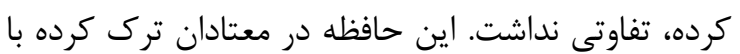
غيرمعتادان يا افراد سالم نيز تفاوت معنادارى نداشت. بهان عبارتى مىتوان كفت كه خطاى مربوط به به حافظه

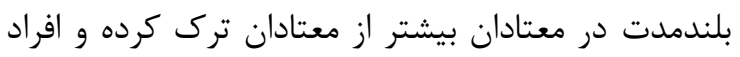

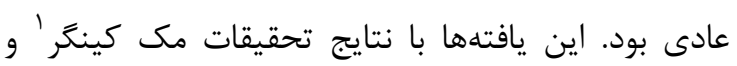

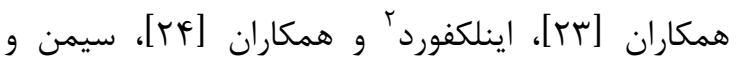

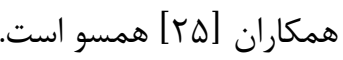

از سويى به منظور مشخص كردن تفاوت ميانگينها در حافظه بلندمدت از آزمون تعقيبى توكى استفاده شد كه نتايج در جدول ب ارائه شده است. نتايج آزمون تعقيبى توكى براى مقايسه ميانكين نمرات كروهها براساس شاخصهاى تفاوت ميانگينها و سطح معنادارى در جدول ب نشان مى دهد كه در عملكرد حافظه

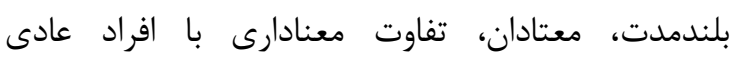

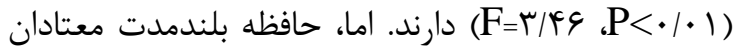

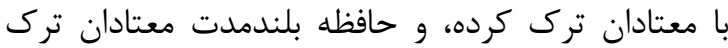

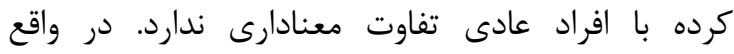

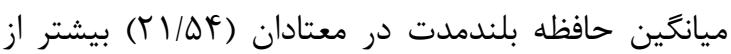

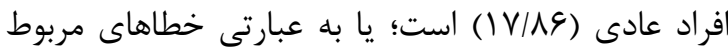
به حافظه بلندمدت در معتادان بيشتر از افراد غيرمعتاد

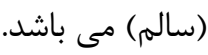


ديخر، فرايندى روانشناختى خواهد داشت كه اين

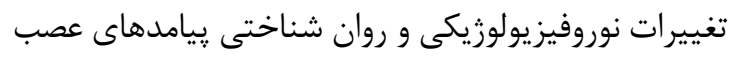
- روان شناختى را به دنبال خود ايجاد مى كنند. بنابراين

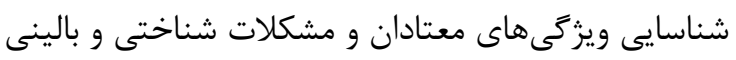
آنان مى تواند براى درمان موفقتر و كمك بيشتر براى ترك اعتيادشان كمك كننده باشد. بنا به الكوى بيروى بيمار از

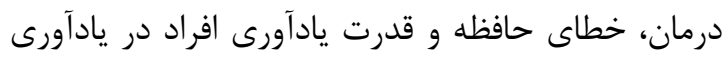

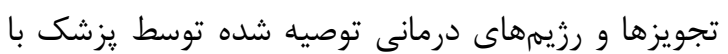

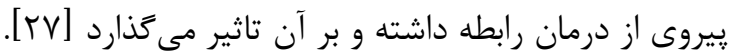
در واقع اولين و مهمترين مانع پيروى از درمان ردان را مشكلات

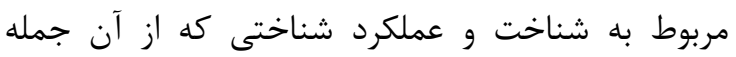
خطاى حافظه مى باشد عنوان كرد؛ بنابراين به نظر مى رسد كه بخشى از علل برگشت اعتياد يا ناتوانى در ترك إنى مى تواند به عدم يُيروى فرد معتاد از يزشك و ورائد درمان مربوط شود كه در اثر تخريب حافظه صورت ميى برد برد كيرد. در واقع، نقص در حافظه كارى و فرايندهاى بازدارى، توانايى سوء مصرف كنند ترى رفتارهاى اعتيادى را به سرعت به مخاطره مى مياندازد

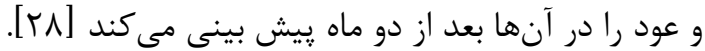

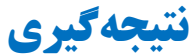

اين يزوهش با محدوديتهايى مواجه بود. عدم امكان نمونه گيرى تصادفى و عدم امكان مطالعه معتادان بر حسب مداد ماده مصرفى و همجنين عدم امكان مطالعه معتادان بر حسب

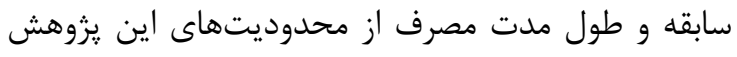

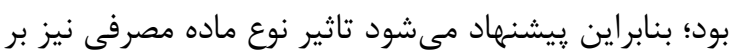
انواع حافظه مطالعه شود، اثر طول مدت مصرف نيز مطالعه شود و از معتادان زن استفاده شود. از سويى با توجه به به

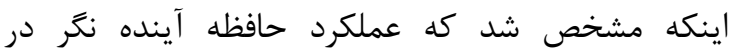
معتادان ضعيف است، مى توان با آموزشهاى مرتبط و ائناف تلاش براى ترميم اين حافظهها به معتادان كمك كرد كه

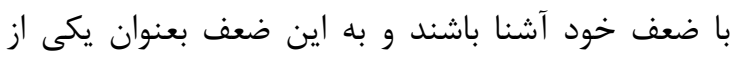

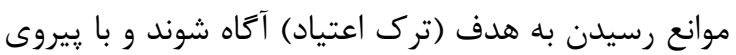

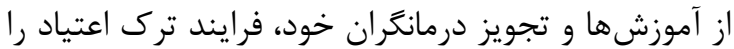
راحتر يشت سر بخذارند و از خطر بركشت دوباره به

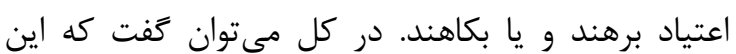
يافتهها براى درمانكران حوزه اعتياد تلويحات عملى و وناهن كاربردى زيادى به همراه دارد. بنابراين، انتظار مىرود كه دهان
طبق يافتهاى مك كينكر و همكاران [بr] افسردههاى داراى سوء مصرف مواد، در بازيابى حافظه شرح حال خود

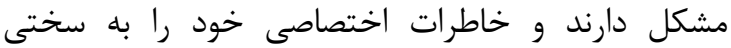

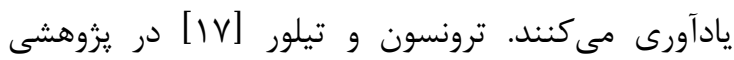
نشان دادند مصرف كنند

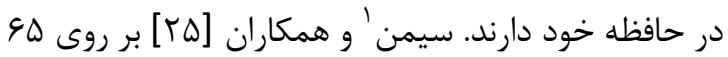

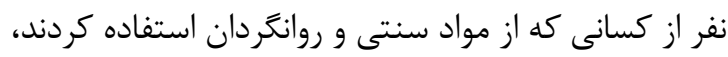
نشان دادند كه آنها در مقايسه با افراد سالم در زمينه آنهاى شناختى نظير يادآورى، بازشناسى لغات، حافظهٔ كارى و

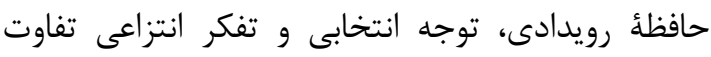

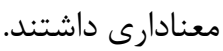
به اعتقاد لتوا [ها] ] افراد وابسته به مواد و افراد مبتلا به عود، بر خلاف افراد ترك كرده توان ناديده گرفتن نشانه

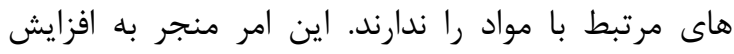

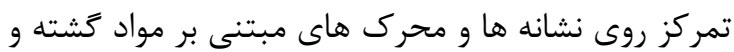
وسوسه مصرف مواد را افزايش مى دهد دهد و از سويى

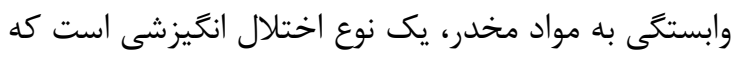
به علت بلوكه شدن مدارهاى عصبى مربوط به حافظه و يادكيرى به وجود مى آيد و در واقع مطالعات تصويربردارى داري مغزى بر روى افراد وابسته به مواد مخدر نشان داده اند كه دئ دادي الكوى فعاليت مغز و كيفيت ماده سفيد كه مرتبط با توجه و حافظه هستند، در اين افراد نسبت به افراد عادى

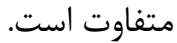

بنابراين حافظه و يادآورى يكى از عوامل موثر بر ييروى در

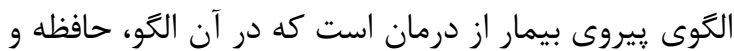

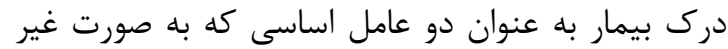

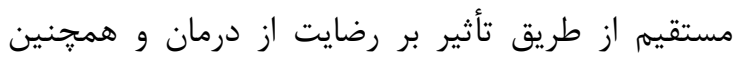

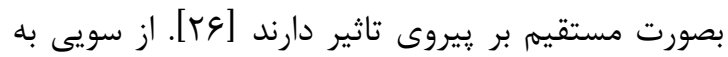
هر ميزان كه افراد از حافظه بهتر و خطاى حافظه كمترى برخوردار باشند، ميزان پيروى از درمان در آنان بيشتر مى إنى

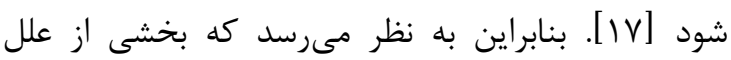
برگشت اعتياد يا ناتوانى در ترك مى تواند به عدم يِيروى فرد معتاد از يزشك و فرايند درمان مربوط شود كه در اثر تران تران تخريب حافظه بلندمدت صورت مى كيرد

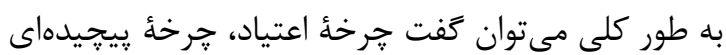
است كه از يك سو، فرآيندى نوروفيزيولوزيكى و از سوى

\section{1-Simon}




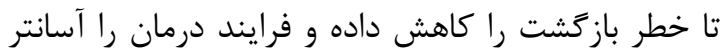
كند. بنابراين شناسايى فرايندهاى حافظه كوتاه مدت و و بلندمدت بر اعتياد مى تواند تلويحات كاربردى مطلوبى در زمينه تشخيص، درمان و ييشخيرى سوء مصرف مواد داشته باشد.

\section{تشكر و قلر دانه} نويسندكان بر خود لازم مى دارند از كليه افرادى كه در انجام اين تحقيق ما را حمايت كردند، تشكر و قدردانى نمايند. اين طرح بدون حمايت مالى انجام شده است. 


\section{References}

1. Galanter M, Innovations: Alcohol and drug abuse: Spirituality in alcoholics anonymous: A valuable adjunct to psychiatric services, Psychiatric Services 2006; 5(3): 307-309.

2. Khalatbari J, Bazarganiyan N, [Comparison the depression, anxiety and stress in intravenous drug abusers, with and without HIV/ AIDS], Journal of Guilan University of Medical Sciences 2011. 20(78); 76-83[Persian].

3. Fontain KL. Mental health nursing, 5nd ed. London: Prentice Hall; 2007, P. 146-156.

4. West R, Theory of addiction, Blackwell Publishing, Oxford; 2006.

5. Parvizi S, Ahmadi F, Nikhbakhtnasrabadi A, [Addiction in Adolescents: A Qualitative Study]. Thought and Behavior in Clinical Psychology 2004. 10(3); 250-257[Persian].

6. Martin PR, Weinberg BA, Bealer BK, Healing addiction: An in tegratedpharmacopsychosocial approach to treatment, United States of America, John Wiley \& Sons; 2007.

7. Lundgren M, Amodeo M, Chassle D, Mental health status, drug treatment use and needle sharing among injection drug users, AIDS Educ Prev 2005, 17(6); 525-39.

8. Asghari MJ, Deshkam M, Azadfallah P, [Productivity comparisons nerve activity- Psychological (reaction time) in addicts and normal people], Studies and Psychology, Ferdosi University 2009, 10(1); 47-61[Persian].

9. Gshoni M, [Quantification of brain signals during memory, MSc Thesis, Faculty of Engineering], Islamic Azad University of Mashhad; 2005[Persian].

10.Atkinson, RC, Smith EO, Bam DJ, Hvksma S. Hilgard psychology (Vol. I), Translated by H. Rafiee, Tehran: Publications Arjeman; 2005[Persian].

11.Heishman SJ, Kleykamp BA, Singleton EG, Meta-analysis of the acute effects of nicotine and smoking on human performance, Psychopharmacology (Berl) 2010, 210(4); 453-69.

12.Roberts GM, Nestor L, Garavan H, Learning and memory deficits in ecstasy users and their neural correlates during a facelearning task, 2009, www.BioInfoBank Library.com

13. Noe X, Brevers D, Bechara A, A neurocognitive approach to understanding the neurobiology of addiction, Current Opinion in Neurobiology 2013; 23: 632-638

14.Park RJ, Goodyer IM, Teasdale JD, Effects of induced rumination and distraction on mood and over general autobiographical memory in adolescent major depressive disorder and controls, J of Child Psych and Psych 2004; 45: 996- 1006.

15.Latvala A, Cognitive Functioning in Alcohol and Other Substance Use Disorders in Young Adulthood: A Genetic Epidemiological Study [dissertation],[Finland]: University of Helsinki, Institute of Behavioral Sciences and Department of Public Health Helsinki; 2011. P 138.

16.Solowij N, Battisti R, The chronic effects of cannabis on memory in humans: a review 2008; www.BioInfoBank Library.com.

17.Tronson NC, Taylor JR, Addiction: a drug-induced disorder of memory reconsolidation, Current Opinion in Neurobiology 2013; 23: 1-8.

18. Kuyken W, Howell R, Facets of autobiographical memory in Adolescents with major depressive disorder and never- depressed controls, Cognition and Emotion 2000; 20 (3/4): 466-487.

19. Williams JMG, Barnhofer T, Crane C, Hermans D, Raes F, Watkins E, Dalgleish T, Autobiographical memory specificity and emotional disorder, Psychological Bulletin 2007; 133: 122148.

20.Vrielynck N, Deplus S, Philippot P, Over general Autobiographical Memory and Depressive Disorder in Children, J of Clinical Child and Adolescent Psychology 2007; 36(1): 95-105.

21. Sutherland K, Bryant RA, Rumination and over general autobiographical memory, Behavior Research and Therapy 2007; 45: 2407-2416.

22.Crawford JR, Henry JD, Ward AL, Blake J, The Prospective and Retrospective Memory Questionnaire (PRMQ): Latent structure, normative data and discrepancy analysis for proxy-ratings, British Journal of Clinical Psychology 2006; 45: 83-104.

23.Mackinger HF, Leibetseder MF, Kunz-Dorfer AA, Fartacek RR, Whitworth AB, and Feldinger FF, Autobiographical memory predicts the course of depression during detoxification therapy in alcohol dependent men, J of Affect Disorder 2004; 78(1): 61-65. 
24.Indlekofer F, Piechatzek M, Daamen M, Glasmacher C, Lieb R, Pfister H, Tucha O, Lange KW, Wittchen HU, Schütz CG, Reduced memory and attention performance in a population-based sample of young adults with a moderate lifetime use of cannabis, ecstasy and alcohol, 2009. WWW. BioInfoBank Library.com.

25.Simon SL, Domier C, Carnell J, Brethen P, Rawson R, Ling W, Cognitive impairment in individuals currently using metham phetamine, The American Journal on addiction 2000; 9: 222-237. 26. Quednow BB, Jessen F, Kuhn KU, Maier W, Daum I, Wagner M, Memory deficits in abstinent MDMA (ecstasy) users: neuropsychological evidence of frontal dysfunction 2006; Www. BioInfoBank Library.com.

27.Zare H, Taraj SH, [Premenstrual syndrome effect on short-term memory, long-term, futureoriented women with this syndrome], IJOGI 2009; 4(4): 45-53[Persian].

28. Noel X, Van der Linden M, Schmidt N, Sferrazza R, Hanak C, Le Bon O, De Mol J, Kornreich C, Pelc I, Verbanck P, Supervisory attention system in nonmagnetic alcoholic men, Archives of general psychiatry 2001; 58 (12): 1152-1158. 


\title{
Comparison of long-term and short-term memory in male addict Opium, have left addicts, and healthy
}

\author{
Ghanbari $S^{l}$, Akbarzadeh $D^{2}$ *, AkbarzadehH ${ }^{3}$, Esmailpour $\mathrm{Kh}^{4}$
}

\begin{abstract}
${ }^{1} \mathrm{MSc}$ of clinical psychology, Science and research branch Islamic Azad University, Tabriz, Iran ${ }^{2} \mathrm{MSc}$ of educational psychology, Islamic Azad University, Tabriz, Iran

${ }^{3} \mathrm{MSc}$ of Jurisprudence and Principles of Islamic Law, Islamic Azad University, Tabriz, Iran

${ }^{4}$ Associate Professor of consultation, Faculty Member, Tabriz University, Tabriz, Iran

*Corresponding Author: Islamic Azad University, Tabriz, Iran

Email: zakeri.ba65@gmail.com
\end{abstract}

\section{Abstract}

Background \& Objectives: Addiction is a physical illness, mental, social and spiritual and one serious injury seeking drug a brain injury. The main aim of the present study was to compare of long-term and short-term memory in male addict Opium, have left addicts, and healthy.

Materials \& Methods: The study method was descriptive, causal-comparative. The target population of this study were male addict, have left addicts, and healthy that 35 addicted, 32 have left addicts, 35 healthy selected by purposive sampling. For data collecting prospective and retrospective memory Questionnaire (PRMQ) were used. Data were analyzed by using of multivariate (MANOVA) and Tukey test.

Results: The results showed that there were significant differences in long-term memory performance between male addicts, have left addicts, and healthy $(0.05>P)$, but there was no significant difference in short-term memory performance. Tukey test results also showed that long-term memory mean more than in addicts and have left addicts, and healthy.

Conclusion: Thus, The increase duration of drug further impairs long-term memory impairs and therefore makes it more difficult to quit drugs.

Keywords: Long-term memory, short-term memory, addict, have left addicts, healthy people. 